\title{
PROCEEDINGS OF THE BIOCHEMICAL SOCIETY
}

The 519th Meeting of the Society was held at University College Dublin on Thursday and Friday, 30 September and 1 October 1971, when the following papers were presented:

\section{COLLOQUIUM ON 'MUSCLE STRUCTURE AND FUNCTION'}

\section{The Relaxing Protein System and the Regula- tion of the Myofibrillar Adenosine Triphos- phatase}

By S. V. Perry. (Department of Biochemistry, University of Birmingham, Birmingham B15 STT, U.K.)

The relaxing protein system consists of a complex of protein factors, incorporated into the structure of the myofibril, that enables the $\mathrm{Mg}^{2+}$-stimulated ATPase* of actomyosin to be regulated by changes in the free $\mathrm{Ca}^{2+}$ concentration occurring within the muscle cell. The $\mathrm{Mg}^{2+}$-stimulated ATPase of pure (sometimes called 'desensitized' or 'synthetic') actomyosin is fully active in the absence of $\mathrm{Ca}^{2+}$. In the presence of the relaxing protein system, however, the $\mathrm{Mg}^{2+}$-stimulated ATPase activity is strongly inhibited if the $\mathrm{Ca}^{2+}$ concentration is less than $0.01 \mu \mathrm{M}$, but when it rises above $1.0 \mathrm{~mm}$ the $\mathrm{Mg}^{2+}$-stimulated ATPase becomes fully active. Thus in situ the myofibrillar ATPase and hence contractile activity is regulated by the movement of $\mathrm{Ca}^{2+}$ to and from the vesicles of the sarcoplasmic reticulum.

Ebashi (1963) proposed that the relaxing protein system consisted of tropomyosin and a new protein that he named troponin. It now appears unlikely that troponin is a unique entity, but is probably a complex of three main protein components, the relative amounts of which are determined by the method of preparation. These have been described as the calcium-sensitizing factor, the inhibitory factor and a protein of molecular weight 37000 , the precise function of which is as yet undetermined (Schaub \& Perry, 1971; Wilkinson, Perry, Cole \& Trayer, 1971).

The inhibitory factor is a highly polar and rather basic protein of molecular weight 23000 , which has not yet been shown to inhibit any ATPase other than the $\mathrm{Mg}^{2+}$-stimulated ATPase of actomyosin. Purified preparations of the 23000 dalton component require tropomyosin in roughly half molar proportions for full inhibitory activity.

* Abbreviation: ATPase, adenosine triphosphatase. $d^{*}$
In contrast with the inhibition obtained with the complete relaxing protein system this inhibition is insensitive to $\mathrm{Ca}^{2+}$. The inhibitory factor is the main active inhibitory component of troponin B preparations obtained by Hartshorne \& Mueller (1968), which also have been shown to contain the 37000-dalton component (Wilkinson et al. 1971). It is probably identical with the troponin fraction 2 reported by Greaser \& Gergely (1971).

The inhibitory factor appears to interact with actin, thus preventing this protein from exerting its effect on the enzymic centre of myosin that enables the latter protein to hydrolyse $\mathrm{MgATP}^{2-}$ (Schaub \& Perry, 1971).

During certain preparative procedures the inhibitory factor is partially degraded to a protein of molecular weight about 14000 (J. M. Wilkinson, S. V. Perry, H. Cole \& I. P. Trayer, unpublished work). This protein possesses similar inhibitory activity to the parent molecule, but no longer contains the cysteine residues present in the original inhibitory factor and which are not essential for its biological activity (Schaub \& Perry, 1971). The preparations of the 14000-dalton component so far obtained have a variable requirement for tropomyosin for full inhibitory activity (J. M. Wilkinson, S. V. Perry, H. Cole \& I. P. Trayer, unpublished work).

The calcium-sensitizing factor is a highly polar protein of molecular weight 18000-19000 with an excess of acidic amino acids. It is the active component of troponin A preparations (Hartshorne \& Pyun, 1971) and is the target protein for $\mathrm{Ca}^{2+}$ in the relaxing protein system. Its strong affinity for $\mathrm{Ca}^{2+}$ is such that on gel filtration is 2-6 M-urea this bivalent cation is still bound, in strong contrast with the behaviour of myosin, actin, tropomyosin or inhibitory factor under similar conditions (Schaub, Perry \& Häcker, 1972). It is probably identical with the troponin fraction 4 reported by Greaser \& Gergely (1971) and the troponin fraction III reported by Ebashi, Wakabayashi \& Ebashi (1971), as judged by amino acid analyses. On the other hand the latter workers designate their troponin II as the $\mathrm{Ca}^{2+}$-receptive protein. 
Two properties of the calcium-sensitizing factor can be distinguished. The first is that it can neutralize the inhibitory activity of the inhibitory factor. This property is exhibited in the absence of tropomyosin with those inhibitory-factor preparations that do not require added tropomyosin for activity. In these circumstances removal of traces of $\mathrm{Ca}^{2+}$ from the system by the addition of ethanedioxybis(ethylamine)tetra-acetate do not restore inhibition, as occurs with complete relaxing protein systems. On subsequent addition of tropomyosin the $\mathrm{Ca}^{2+}$-sensitivity of the $\mathrm{Mg}^{2+}{ }_{\text {-stimulated }}$ ATPase is restored and the whole relaxing protein system is reconstituted.

Under conditions of preparation involving prolonged exposure to ethanedioxybis(ethylamine)tetra-acetate a modified form of calcium-sensitizing factor can be prepared that, although it neutralizes the inhibitory factor, no longer restores $\mathrm{Ca}^{2+}$. sensitivity to the system even in the presence of tropomyosin (Schaub et al. 1972). It is suggested that the regulation of the neutralizing action of the inhibitory factor by $\mathrm{Ca}^{2+}$ is regulated through an allosteric site on the calcium-sensitizing factor.

The role of the 37000-dalton component is not yet clear. As prepared by chromatography in dissociating conditions it does not replace inhibitory factor, calcium-sensitizing factor or tropomyosin in the relaxing protein system. It is a different protein from these last three proteins as judged by its amino acid analysis. Although its amino acid composition is similar to that of the troponin I described by Ebashi et al. (1971) of molecular weight 40000 , the latter in some reported functions resembles the inhibitory factor. Ebashi et al. (1971) claim complete reconstitution of the relaxing protein system with tropomyosin, troponin I and troponin II. Greaser \& Gergely (1971), however, report results that suggest that, in addition to tropomyosin, inhibitory factor and calcium-sensitizing factor, a 35000-dalton component, troponin fraction 3 (possibly corresponding to the 37000 dalton component described by Wilkinson et al. 1971) is also required. In our hands reconstitution of the relaxing protein system has been obtained in some circumstances with tropomyosin, inhibitory factor and calcium-sensitizing factor alone.

The extreme difficulties experienced in separating the components of the troponin complex cleanly from each other are probably responsible for the uncertainties still remaining in the nature of the relaxing protein system. Thus on the balance of evidence currently available it can be concluded that the troponin complex consists of three proteins, two of which have well-defined activities whereas further work is required to decide on the precise role of the third component of 37000 molecular weight.
Ebashi, S. (1963). Nature, Lond., 200, 1010.

Ebashi, S., Wakabayashi, T. \& Ebashi, F. (1971). J. Biochem., Tokyo, 69, 411.

Greaser, M. L. \& Gergely, J. (1971). Fedn Proc. Fedn Am. Socs exp. Biol. 30, 1309 (Abstr.).

Hartshorne, D. J. \& Mueller, H. (1968). Biochem. biophys. Res. Commun. 31, 647.

Hartshorne, D. J. \& Pyun, H. Y. (1971). Biochim. biophys. Acta, 229, 698.

Schaub, M. C. \& Perry, S. V. (1971). Biochem.J.123, 367. Schaub, M. C., Perry, S. V. \& Häcker, W.(1972). Biochem. $J$. (in the Press).

Wilkinson, J. M., Perry, S. V., Cole, H. \& Trayer, I. P. (1971). Biochem.J. 124, 55P.

\section{The Calcium Pump in the Sarcoplasmic Reticulum}

By P. F. Dugan. (Department of Biochemistry, University College, Dublin 2, Irish Republic)

The degree of contraction of a muscle cell is controlled by the intracellular concentration of $\mathrm{Ca}^{2+}$. When the concentration of this ion is increased above about $0.1 \mu \mathrm{M}$ by a nervous stimulus the cell changes from a resting to an active state. Full contraction occurs at about $1.0 \mu \mathrm{M}-\mathrm{Ca}^{2+}$. In skeletal muscle the source of the regulatory $\mathrm{Ca}^{2+}$ is the internal membrane system, the sarcoplasmic reticulum. During the relaxation process the $\mathrm{Ca}^{2+}$ concentration within the myofilaments is lowered once again to below $0.1 \mu \mathrm{M}$ by the action of the ATP-requiring calcium pump of the sarcoplasmic reticulum (Ebashi \& Endo, 1968).

The characteristics of this pump system have been extensively investigated since Ebashi \& Lipmann (1962) showed its presence in fragmented sarcoplasmic reticulum of homogenized muscle cells. Earlier reports suggested that univalent cations either had no effect (Martonosi \& Feretos, 1964) or inhibited $\mathrm{Ca}^{2+}$ uptake (Lee, Tanaka \& Yu, 1965). On homogenization in sucrose medium without added salts the endogenous $\mathrm{K}^{+}$concentration of the microsomal fraction was lowered sufficiently to show that $\mathrm{K}^{+}$increased $\mathrm{Ca}^{2+}$ uptake about threefold, the decreasing order of effectiveness being: $\mathrm{K}^{+}>\mathrm{Na}^{+}>\mathrm{NH}_{4}^{+}>\mathrm{Rb}^{+}>\mathrm{Cs}^{+}>\mathrm{Li}^{+} . \mathrm{Li}^{+}$has only a slight effect. On incubation of the microsomal fraction in the macrocyclic polyether dicyclohexyl-18-crown-6 (Pedersen, 1968), which forms a stable complex with $\mathrm{K}^{+}$, the cation lying in the hole of the polyether ring, the rate of $\mathrm{Ca}^{2+}$ uptake falls to a low value. The maximum rate of transport was restored when $\mathrm{K}^{+}$was added to the medium, indicating an absolute requirement of this ion by the $\mathrm{Ca}^{2+}$-uptake system. $\mathrm{Th}^{+}$, which can replace $\mathrm{K}^{+}$in the activation of acetyl phosphatase, $p$ nitrophenyl phosphatase (Inturrisi, 1969a) and 